\title{
Adenocarcinoma in Tubulovillous Adenoma
}

National Cancer Institute

\section{Source}

National Cancer Institute. Adenocarcinoma in Tubulovillous Adenoma. NCI Thesaurus. Code C4145.

A non-invasive or invasive adenocarcinoma arising from a tubulovillous adenoma. 